\title{
CHEMICAL ELEMENT PROFILES IN COMMERCIAL WOVEN FABRIC COMBINING LASER-INDUCED BREAKDOWN SPECTROSCOPY AND CHEMOMETRICS
}

\author{
M. Cardoso Santos, C. Dai, \\ and F. Manhas Verbi Pereira*
}

UDC 543.42

High-heterogeneity solid woven fabric samples were investigated using laser-induced breakdown spectroscopy (LIBS) and chemometrics. Many emission lines were relevant to characterize this material at the surface and in deeper layers of fibers. Differences among dyes and fibers were clearly observed. The scores maps showed the possibility of comparing the chemical compositions of the dye and fiber independent of the print of fabric. Variations in the composition were verified by carrying out a pattern for mapping using a sophisticated LIBS system. This screening can provide a fast evaluation of samples and may associate this information with classification, authenticity or even for forensic analysis of fabric materials.

Keywords: woven fabric, laser-induced breakdown spectroscopy, chemometrics.

Introduction. In recent decades, the globalization of markets has imposed significant changes in the Brazilian textile industry. In the past, national production supplied almost exclusively to the domestic market. This framework has continuously changed, and due to economic openness, low-cost products from Asia account for almost $90 \%$ of the volume of our domestic market [1].

In this context, studies have been conducted to evaluate the presence of possible toxic elements in imported textile goods and clothing. Since clothing has the function of protecting the body, woven fabric promotes direct contact of textile dyes with human skin. Some studies suggest the possibility of migration of metals or other chemical species through the sweat of the body system $[2,3]$. Regarding textile dyes, there is not enough information about their potential risks to the health of consumers; available toxicological data have shown effects ranging from allergies to possible genetic changes [4]. Current studies related to possible effects of textile dye contact with the skin have focused on allergies and dermatitis, as previously mentioned. However, toxic dyes in the human body can induce harmful effects in cells, including DNA damage, which is related to various diseases, including certain types of cancer [5].

Toxic elements can easily be found in various sectors of the textile industry because they are often used in different textile processes, such as complexing agents in dyes, stripping agents, oxidizing materials, antifungal agent mordants, and compounds to prevent odor. In addition, they are applied to increase the durability of dye [6]. Considering the toxic aspects, several substances in textile products are relevant for chemical analysis. These analyses are vital to verify compliance with regulations of the presence and levels of prohibited or restricted substances and to characterize and manage them as well as to broader issues, such as classification, traceability, forensic analysis, and authenticity. Laser-induced breakdown spectroscopy (LIBS) $[7,8]$ combined with chemometrics is an analytical technique that can be used to evaluate solid samples and compose maps of the chemical element distribution for analytical purposes $[9,10]$.

The importance of the study of these elements is not restricted to the safety of consumers of these materials but also to the safety of workers in the textile industry, as well as environmental concerns regarding the disposal of these materials. The threshold limit values have not been defined yet for legislations in several countries. This topic is new and slightly exploited and this work can be a beginning to think about the environmental impact from the fabric goods.

\footnotetext{
*To whom correspondence should be addressed.
}

Universidade Estadual Paulista (UNESP), Instituto de Química, Departamento de Química Analítica, Rua Professor Francisco Degni, 55, Araraquara, SP 14800-060, Brazil; email: fabiola@iq.unesp.br. Abstract of article is published in Zhurnal Prikladnoi Spektroskopii, Vol. 85, No. 3, p. 512, May-June, 2018. 
Experimental. Eight samples from commercial woven fabrics purchased at local markets were investigated. The patterns of the samples were colorful prints, which was the criteria to represent a very wide variation of textile dyes. According to the manufacturers, the composition of this set of samples was as follows: 4 viscolycra (V) samples (viscose and elastane, denoted as V01, V02, V03, and V04), two liganete (L) samples (polyester, denoted as L01 and L02), and two neoprene (N) samples (polychloroprene, denoted as N01 and N02).

Procedures of mineral extraction. Before direct solid sample analysis, textile samples were submitted to preliminary chemical analysis for the determination of their metal contents. In this case, two different procedures were also tested considering the possibility of the textile contacting the skin and the toxicity of the dyes. For these analyses, samples of approximately $0.5 \mathrm{~g}$ were cut with the help of a ceramic knife; then, they were dried for $48 \mathrm{~h}$ at $60^{\circ} \mathrm{C}$ to avoid any possibility of contamination and all samples were manipulated without skin contact of the chemical analyst [11].

Therefore, raw samples were kept in an artificial sweat solution that was prepared as recommended by International Standard ISO/FDIS 3160/2 [12]. Another procedure was the mineralization of the samples performed with the help of a microwave oven (Speedwave 4, Berghof, Eningen, Germany) equipped with DAK 100 high-pressure vessels made of $\mathrm{TFM}^{\mathrm{TM}}$-PTFE. Mineralization was performed with a mixture of $5 \mathrm{~mL}$ of $14 \mathrm{~mol} / \mathrm{L}$ sub-boiling nitric acid and $5 \mathrm{~mL}$ of $30 \%$ $(\mathrm{m} / \mathrm{v})$ hydrogen peroxide. The microwave oven program was executed in two steps: (1) from room temperature up to $160^{\circ} \mathrm{C}$ in $5 \mathrm{~min}$ with a holding time of $5 \mathrm{~min}$; (2) from 160 to $220^{\circ} \mathrm{C}$ in $2 \mathrm{~min}$ with a holding time of $15 \mathrm{~min}$. The maximum allowed pressure was 80 bar. The final volumes were adjusted with $1 \% \mathrm{HNO}_{3}$ to $50 \mathrm{~mL}$ in volumetric flasks.

After the extraction, for both methods, the following eight elements were determined: $\mathrm{Cd}, \mathrm{Co}, \mathrm{Cr}, \mathrm{Cu}, \mathrm{Fe}, \mathrm{Ni}, \mathrm{Pb}$, and Ti. For sweat extraction, the analytical curve for the first seven elements was from 0.05 to $2.00 \mathrm{mg} / \mathrm{kg}$, and the analytical curve ranged from 0.05 to $10.0 \mathrm{mg} / \mathrm{kg}$ for $\mathrm{Fe}$. In the case of the mineralization procedure, the concentration values ranged from 0.50 to $5.0 \mathrm{mg} / \mathrm{kg}$, with Fe being the exception, where the values were between 5.0 and $80.0 \mathrm{mg} / \mathrm{kg}$. The determinations were carried out using an inductively coupled plasma optical emission spectrometry (ICP OES) instrument (iCAP 6000, Thermo Scientific, Waltham, USA).

LIBS mapping. The LIBS instrument used was a commercial J200 LIBS system from Applied Spectra (Fremont, California, USA) with a Nd:YAG $(1064 \mathrm{~nm})$ laser source. For the spectral line information of each element, the Aurora software package (Applied Spectra) and database from the National Institute of Standards and Technology (NIST) were consulted. The laser energy applied for the experiments was $80 \mathrm{~mJ}$, with a delay time of $0.5 \mu$ s and a spot size of $125 \mu \mathrm{m}$. The duration of laser pulse and the laser fluence were $10 \mathrm{~ns}$ and $650 \mathrm{~J} / \mathrm{cm}^{2}$, respectively.

In each sample, an area of $400 \mathrm{~mm}^{2}$ was analyzed. In this area, 20 lines and 20 columns (400 points) were analyzed, and five laser pulses were performed per point. The distance between the lines and columns was $1 \mathrm{~mm}$. A total of 2000 spectra were obtained for each sample. A single spectrum had 12,288 variables comprising emission lines from 186 to 1042 $\mathrm{nm}$. The spectral information was recorded using a 6-channel charge-coupled device (CCD) spectrometer: channel 1 goes 186-nm, channel 2 from 309 to $460 \mathrm{~nm}$, channel 3 from 460 to $588 \mathrm{~nm}$, channel 4 from 588 to $692 \mathrm{~nm}$, channel 5 from 692 to $884 \mathrm{~nm}$, and channel 6 from $884-1042 \mathrm{~nm}$. The spectral resolution is $<0.1 \mathrm{~nm}$ for UV to VIS and $<0.12 \mathrm{~nm}$ for VIS to NIR. Our system does not allow one to perform measurements with inert atmosphere. However, all experimental conditions were constant, which reinforces that the variations of the elements are relative only to the sample, without interference of the atmosphere. A lab-made computer function for Matlab R2015b (MathWorks, Natick, MA, USA) was applied to generate scores maps. Before the calculation, the data set was normalized and mean-centered. Then, the maps were represented by a four-dimensional (4D) tensor composed of the number of mapped points $\times$ principal components $\times$ number of pulses in the horizontal position $\times$ number of pulses in the vertical position. After the calculations, the output data were as follows: (i) scores represented by 5 pulses $\times 400$ mapped points $(20$ horizontal $\times 20$ vertical $) \times 10$ principal components; (ii) loadings with 5 pulses $\times 12,288$ $\times 10$ principal components, where 12,288 is related to the number of variables of the spectral range of the LIBS instrument from 186 to $1042 \mathrm{~nm}$; and (iii) explained variance for the principal components.

WD XRF measurements. The WDXRF experiments were performed using an ARL Perform'X WDXRF spectrometer (Thermo Scientific, Madison, WI, USA). This equipment is provided with a rhodium X-ray tube that can be operated at a maximum power of $4200 \mathrm{~W}$. The measurements were performed under vacuum environment, with a beam collimation of 29 $\mathrm{mm}$ and analyzer LiF 200 crystal (from 0.176 to $3.889 \AA$, $0.01 \AA$ resolution).

Results and Discussion. The textile fabrics were difficult to analyze by means of a digestion procedure. Commercial fabrics are mostly composed of synthetic fibers, such as long chain polymers, including cellulose, polyester, acrylic, nylon, and polythenes [13]. They are mainly composed of complex structures with covalent bonds between C, H, $\mathrm{O}, \mathrm{N}$, and $\mathrm{S}$ [14]. 
A woven fabric is industrially manufactured by means of interlacing threads. The chemical composition and interlacing process are related to the mechanical and end-use purposes of the product [15].

In textile fibers, the dyeing process is relevant to the appearance of the end-product. Final consumers are not interested in having discoloration issues caused by washing or sweat, for example. The contents of dyes are diversified and include diazo, triazo, or metallic complex chemical groups [16]. In this context, the determinations carried out with ICP OES, independent of the range of the analytical curve, did not have good performance because the concentration values were below the limits of detection. The final acidities of the solutions were very high; consequently, the samples had to be diluted 10 -fold for adjustment of the acidity to $10 \%$, which fatefully caused losses for the initial composition. For the sweat procedure, the total solid content of the samples was high, and thus, the samples were diluted 2 -fold to obtain $2 \%$ of solids content maximum. These facts show the advantage of the LIBS in comparison of ICP OES since the interaction of the laser with the solid sample did not promote any losses for this case.

To overcome these issues, analytical techniques that allow high spatial resolution are used to screen the surface and depth of solid samples, such as woven fabric. LIBS has been shown to have good agreement between the mapping and sensitivity to detect atomic and ionic emission lines for a wide number of inorganic elements as well as some organic ones [7-10].

The information from LIBS spectra is very rich, with several emission lines in a wide range from the ultra-violet region to the beginning of the near infrared. Each spectrum generated by LIBS shows a fingerprint, as well as a certain degree of complexity, which confers, in most cases, a challenge that univariate analysis, as a unique method of data evaluation, cannot circumvent [17].

Another important point is that in the case of solid matrices, the construction of an analytical calibration curve is a difficult task. It is not always feasible to use a certified reference material that is compatible with the analytical matrix under investigation. In addition, reference material related to woven fabric is not commercially available. Moreover, it is important to note that the vast majority of certified reference materials have certified values for masses of the order of $100 \mathrm{mg}$. This fact constitutes a limitation for LIBS because the ablated masses are in micrograms [18].

Thus, a feasible alternative with a good success rate for the treatment of LIBS signals is the use of multivariate methods, such as scores maps $[10,19]$. Evaluation of LIBS spectra by means of scores maps was useful to study the interaction of the laser with the surface and deep layers of the fabric. The information from the chemical maps generated by the scores provided a single 2D plot for surface (first laser pulse) and deep layers of the samples (up to second to fifth laser pulse) in a specific mapped area, which is proportional to a qualitative evaluation of the chemical variations in the sample content. The selection of the mapped area in the sample should be representative taking into account the heterogeneity of the sample analytical matrix.

The possibilities of mapping for a piece of woven fabric are many. The instrument was able to map the surface, including the number of lines and points with distances, according to the type of requested information. Each pulse provided different information. The first pulse provided details about the area visualized by the naked eye, which is the surface of the woven fabric sample. According to how the laser is pulsed on samples, deeper information regarding the composition was detected from the second through fifth pulses. This premise was verified for most of the samples according to Fig. 1. As shown in Fig. 1, the scores maps furnished the distribution of the values related to the chemical information of the emission lines from LIBS and the combinations between them, including the loadings, relative to the presence of chemical elements in these solid samples. Atomic lines are represented in black color with the symbol (I) and ionic lines denoted as (II) were highlighted in orange color. The loadings value represents the most influence variables (elements) from the LIBS spectra to chemical distribution in the scores maps.

The positive values of scores are correlated with positive values of loadings and vice versa for negative values. The emission lines of the elements assigned in the loading plots of Fig. 1c,f,i,l showed more relevant chemical information for the scores maps.

The loading plots showed inorganic and organic emission lines, indicating the presence of many elements in the woven fabric samples. The combination of information between the scores and loadings showed negative values for scores related to inorganic elements for samples denoted as V03, L01, and N01 (Fig. 1c,f,i), respectively. As an example, sample V03 (Fig. 1a) is composed by two different structures. The golden part presented negative scores values (Fig. 1b) and was related to negative loadings values (Fig. 1c) with the presence of the following elements: $\mathrm{Al}, \mathrm{Ca}, \mathrm{Co}, \mathrm{Cu}, \mathrm{Fe}, \mathrm{K}$, and $\mathrm{Na}$. In all cases, special attention should be paid to the inorganic emission lines for $\mathrm{Si}, \mathrm{Fe}, \mathrm{Co}, \mathrm{Ti}, \mathrm{Cu}, \mathrm{Ca}$, and $\mathrm{Mg}$, which are the constituents of dyes responsible for color patterns. The only exception was sample N02 (Fig. 1j), where the organic emission lines represented by negative loading values (Fig. 11) were associated with a white color. Further information regarding the scores maps for the three remaining samples is shown in Fig. S1. 

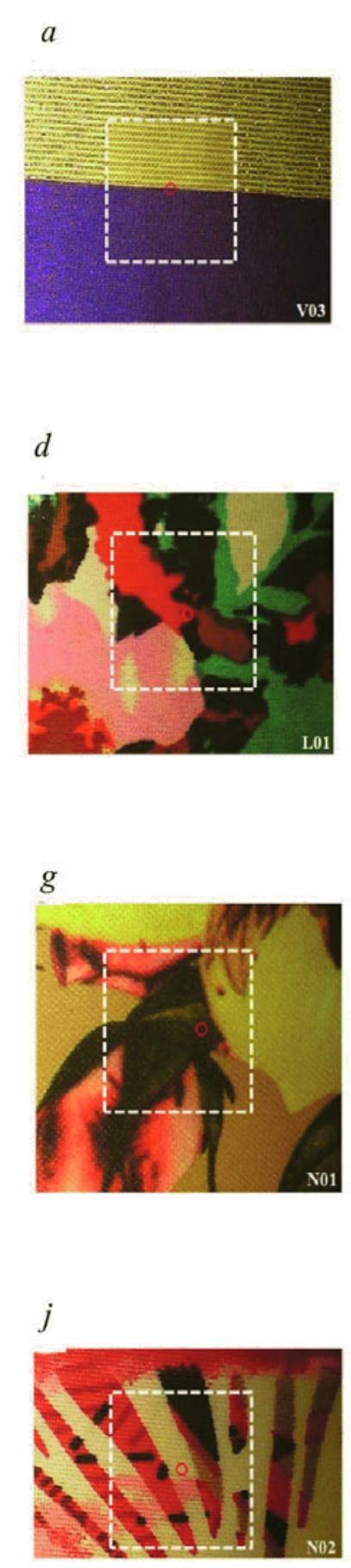

Laser pulse 1-PC1 (63\%) $b$

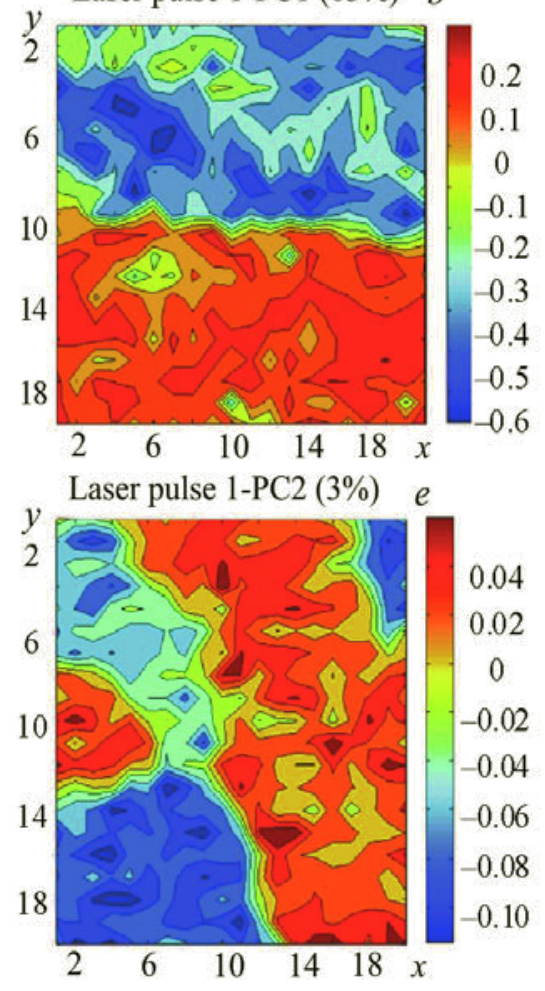

$y$ Laser pulse 1-PC2 (7\%) $h$
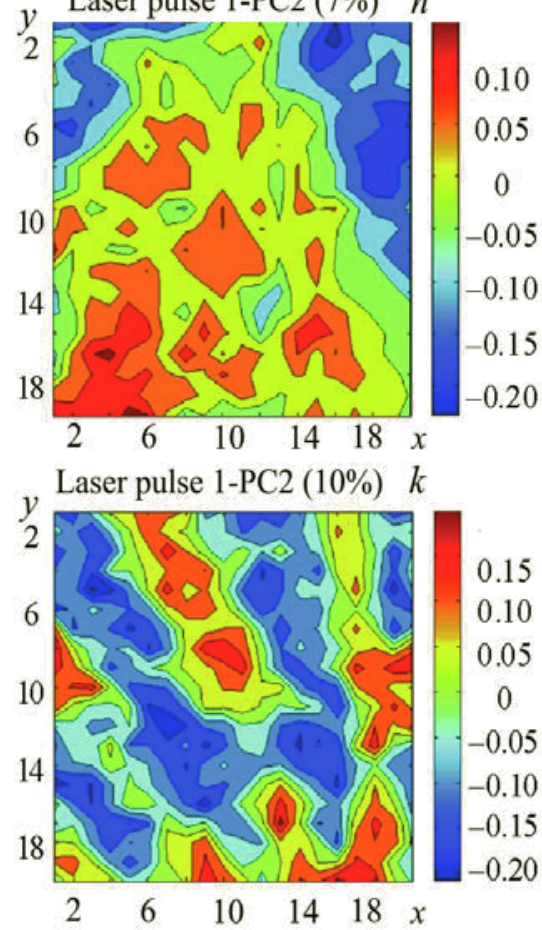

$I$, a. u. c
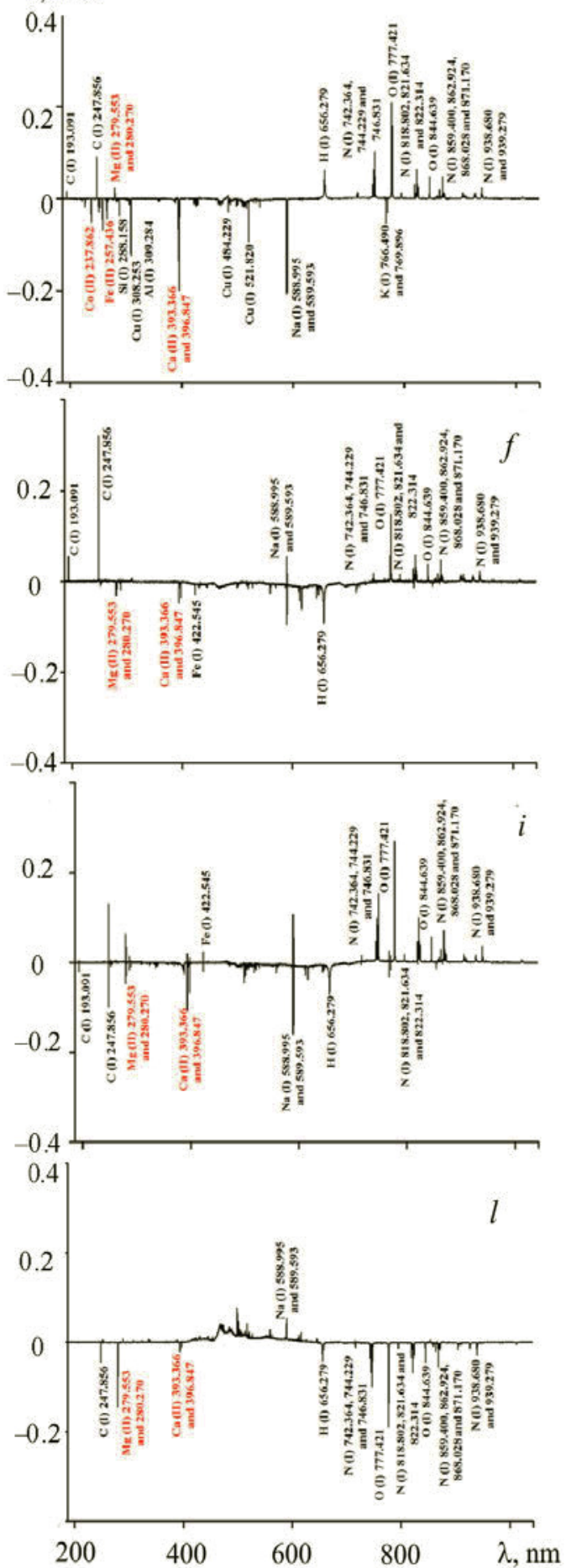

Fig. 1. Woven fabric samples V03, L01, N01, and N02 (a, d, g, j) investigated with LIBS along with their respective scores maps (b, e, h, k) and loadings (c, f, i, l). The white dotted square in parts a, $\mathrm{d}, \mathrm{g}$, and $\mathrm{j}$ represents the ablated area. 

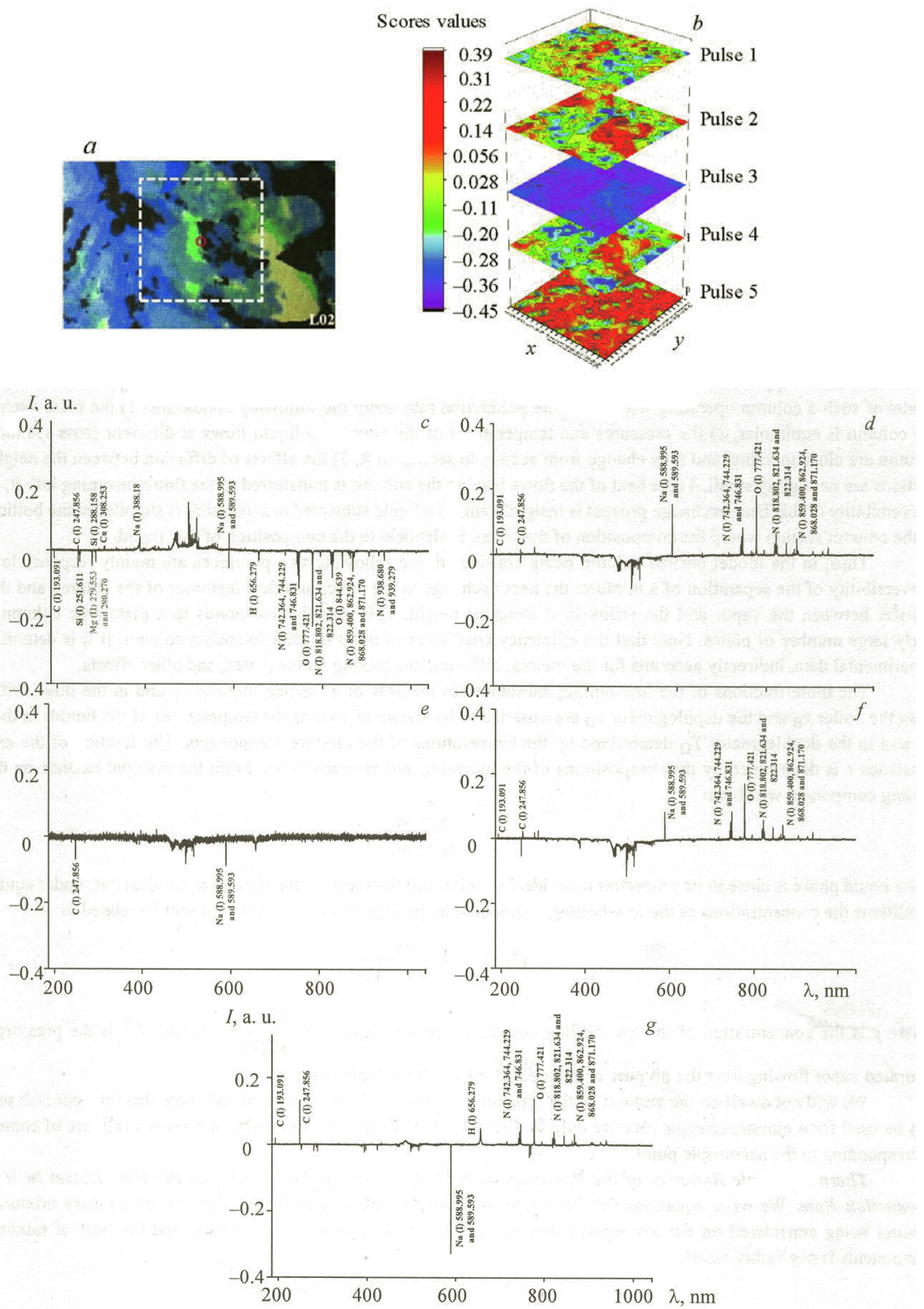

Fig. 2. Liganete woven fabric L02 (a) investigated with LIBS along with the generated scores maps (b) and loadings ( $\mathrm{c}-\mathrm{g}$ ) for the first to the fifth pulses, respectively, with PC2 ( $7 \%$ of explained variance). The white dotted square in part a represents the ablated area. 


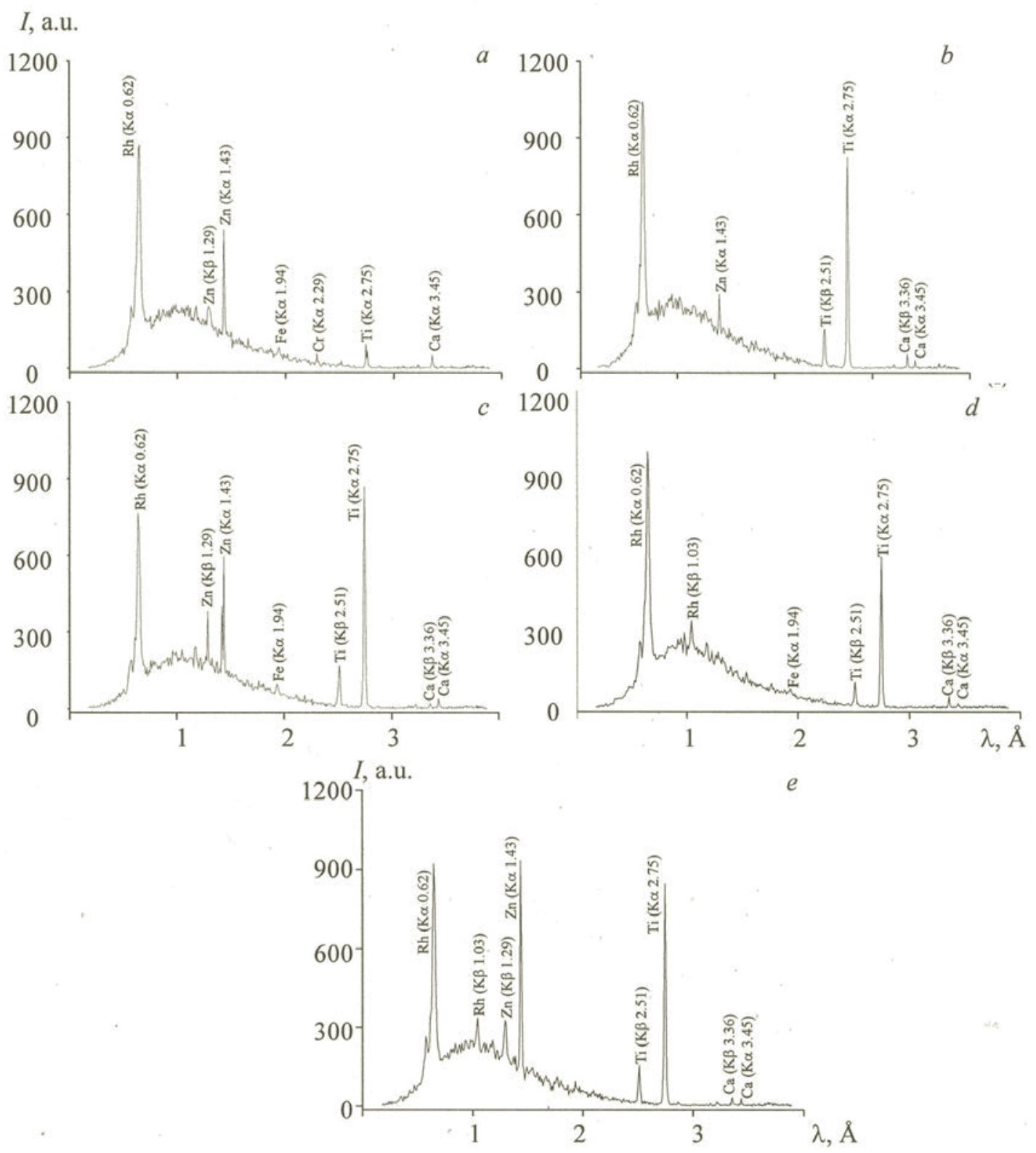

Fig. 3. WD XRF data with the most intense emission for the elements detected in woven fabric samples directly denoted as V03 (a), L01 (b), N01 (c), N02 (d), and L02 (e).

Positive scores were also related with the darker color areas of the woven prints, as shown in the maps of Fig. 1, and this can be verified for the remaining samples in the Supplementary Information. The only sample that was identified in the third pulse was more relevant for sample V04, as these fibers were thicker and rougher to the touch than the other samples, which is shown in Fig. S1h. These findings, in combination with the results of the LIBS and maps, were effective in verifying chemical differences among the dyes and fibers. Figure 2 indicates that the chemical composition can be exploited after each laser pulse focused on the same point. The variations were clearly identified because the dye composition was detected until pulse 2 (Fig. 2b), where the organic and inorganic lines were detected and their magnitudes were higher than others (Fig. 2c-g). After pulse 3, the fiber composition was verifiable because of the presence of the emission line for $\mathrm{C}$ (I) at $247.856 \mathrm{~nm}$ and the decrease of $\mathrm{Na}$ (I) at 588.995 and $589.593 \mathrm{~nm}$, as shown in Fig. 2e.

WD XRF measurements were made directly in the woven fabric samples, and some representative spectra are shown in Fig. 3 and Fig. S2 in order to corroborate the LIBS data. From the spectra is observed the presence of $K_{\alpha}$-fluorescence lines for $\mathrm{Ti}(2.75 \AA)$ and $\mathrm{Ca}(3.45 \AA)$ for all analyzed samples. The elements $\mathrm{Zn}\left(K_{\alpha} 1.43 \AA\right.$ and 
$\left.K_{\beta} 1.29 \AA\right)$ and $\mathrm{Fe}\left(K_{\alpha} 1.94 \AA\right)$ were detected simultaneously for samples V03 (Fig. 3a), N01 (Fig. 3c), and V02 (Fig. S2b). Chromium fluorescence line $\left(K_{\alpha} 2.29 \AA\right)$ was verified for sample V03. The scattering from Rh source $\left(K_{\alpha} 0.62 \AA\right.$ and $K_{\beta} 1.03 \AA$ ) showed high intensity because of the influence of light elements, such as $\mathrm{C}, \mathrm{H}$, and $\mathrm{O}$, on the composition of the woven fabrics.

For instance, $\mathrm{Si}, \mathrm{Cu}$, and $\mathrm{Co}$ were associated with purple color in compounds $\mathrm{BaCuSi}_{2} \mathrm{O}_{6}$ and cobaltous orthophosphate. Silicon was also linked to ultramarine $\left(\mathrm{Na}_{8-10} \mathrm{Al}_{6} \mathrm{Si}_{6} \mathrm{O}_{24} \mathrm{~S}_{2-4}\right)$, which is responsible for the blue color as well, as Cobalt Blue and Cerulean Blue [cobalt (II) stannate]. Copper and Fe produced a blue color by means of synthetic pigments of Calcium copper silicate $\left(\mathrm{CaCuSi}_{4} \mathrm{O}_{10}\right)$, known as Egyptian Blue, and $\mathrm{BaCuSi}_{4} \mathrm{O}_{10}$, known as Han Blue. The yellow color can be linked to the yellow ochre of Monohydrated ferric oxide $\left(\mathrm{Fe}_{2} \mathrm{O}_{3} \times \mathrm{H}_{2} \mathrm{O}\right)$ and titanium yellow. The red color is the result of iron oxide pigments, such as red ochre $\left(\mathrm{Fe}_{2} \mathrm{O}_{3}\right)$. Titanium white is applied to obtain the white color. Cobalt, $\mathrm{Cu}$, and $\mathrm{Mg}$ are constituents of green pigments. Iron and $\mathrm{Si}$ are part of raw umber, a natural pigment. The black color is generated by compounds from $\mathrm{Ti}$ [titanium black $\left(\mathrm{Ti}_{2} \mathrm{O}_{3}\right)$ ] and $\mathrm{Fe}$ [iron black $\left.\left(\mathrm{Fe}_{3} \mathrm{O}_{4}\right)\right]$ [20].

Conclusions. The screening performed in this study can help to evaluate issues regarding the environmental impact and/or to avoid allergic conditions to toxic waste with minimal sample preparation. The scores maps were effective for evaluating each delimited region of woven fabric since each contour included color variations that were reflected in the chemical composition. The LIBS emission lines and the ability to compare the information from the surface and deeper layers were relevant to determining the main compositions of the dyes and fibers, including the pattern of the interlocking fibers. This study can also be used for forensic analysis of fabric material.

Acknowledgments. This research was supported by the São Paulo Research Foundation (FAPESP, Process 2016/00779-6), the National Council for Scientific and Technological Development (CNPq, Process 445729/2014-7), International Association for the Exchange of Students for Technical Experience (IAESTE, C. Dai grant fellowship) and Coordination for the Improvement of Higher Education Personnel (CAPES, M. C. Santos grant fellowship). Special thanks to Daniel Fernandes de Andrade and Lucimar Lopes Fialho for helping during the mineral extraction procedures. The authors are grateful to Analítica and Thermo Scientific for the loan of the ICP OES, WD XRF and microwave oven instruments.

\section{REFERENCES}

1. http://www.desenvolvimento.gov.br//sitio/interna/interna.php?area=5\&menu=1161, accessed July, 2016.

2. J. Lademann, A. Patzelt, M. Worm, H. Richter, W. Sterry, and M. Meinke, Laser Phys. Lett., 6, 759-763 (2009).

3. D. S. Brookstein, Dermatol. Clin., 27, 309-322 (2009).

4. I. Jäger, C. Hafner, and K. Schneider, Mutat. Res., 561, 35-44 (2004).

5. C. J. Lord and A. Ashworth, Nature, 481, 287-294 (2012).

6. I. Rezic and I. Steffani, Microchem. J., 85, 46-51 (2007).

7. J. El Haddad, L. Canioni, and B. Bousquet, Spectrochim. Acta B, 101, 171-182 (2014).

8. J. Kaiser, J. Novotný, M. Z. Martin, A. Hrdlička, R. Malina, M. Hartl, V. Adam, and R. Kizek, Surf. Sci. Rep., 67, 233-243 (2012).

9. D. F. Andrade, E. R. Pereira-Filho, and P. Konieczynski, J. Braz. Chem. Soc., DOI: 10.21577/0103-5053.20160236.

10. R. R. V. Carvalho, J. A. O. Coelho, J. M. Santos, F. W. B. Aquino, R. L. Carneiro, and E. R. Pereira-Filho, Talanta, 134, 278-283 (2015).

11. E. A. Menezes, R. Carapelli, S. R. Bianchi, S. N. P. Souza, W. O. Matos, E. R. Pereira-Filho, and A. R. A. Nogueira, J. Hazard. Mat., 182, 325-330 (2010).

12. ISO (International Organization for Standardization), ISO 3160/2 Watch Cases and Accessories; Gold Alloy Coverings. Part 2. Determination of Fineness, Thickness Corrosion Resistance and Adhesion, ISO, Geneva (2003).

13. A. R. Horrocks and S. C. Anand, Handbook of Technical Textiles, CRC Press, Boca Raton (2000).

14. H. U. Jinlian, Structure and Mechanics of Woven Fabrics, John Wiley \& Sons, Chichester (2000).

15. B. K. Sirkova, AUTEX Res. J., 12, 40-43 (2012).

16. C. C. I. Guaratini and M. V. B. Zanoni, Qui. Nova, 23, 71-78 (2000).

17. G. A. Galbács, Anal. Bioanal. Chem., 407, 7537-7562 (2015).

18. D. A. Cremers and L. J. Radziemski, Handbook of Laser-Induced Breakdown Spectroscopy, 2nd ed., John Wiley \& Sons, Chichester (2013).

19. R. L. Carneiro and R. J. Poppi, Spectrochim. Acta, A, 118, 215-220 (2014).

20. N. N. Mahapatra, Textile Dyes, CRC Press, Boca Raton (2016). 
Supplementary Information
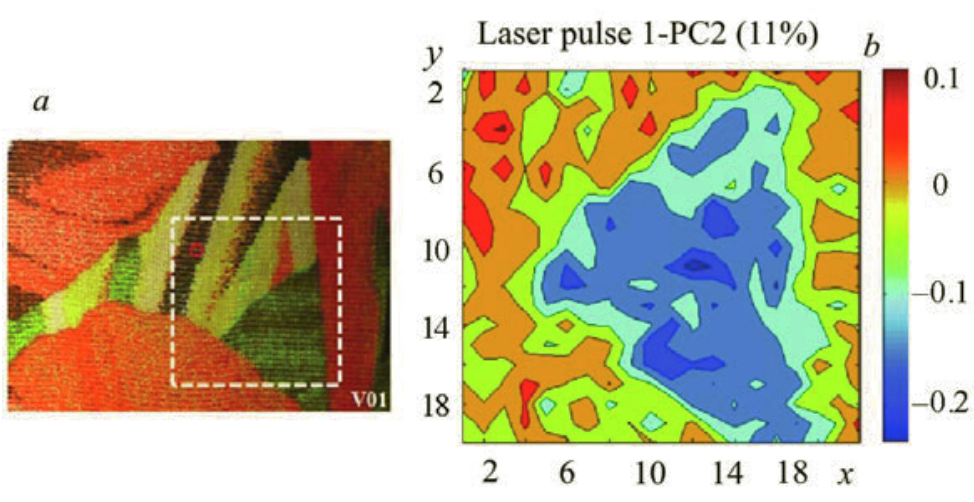

$I$, a. u.
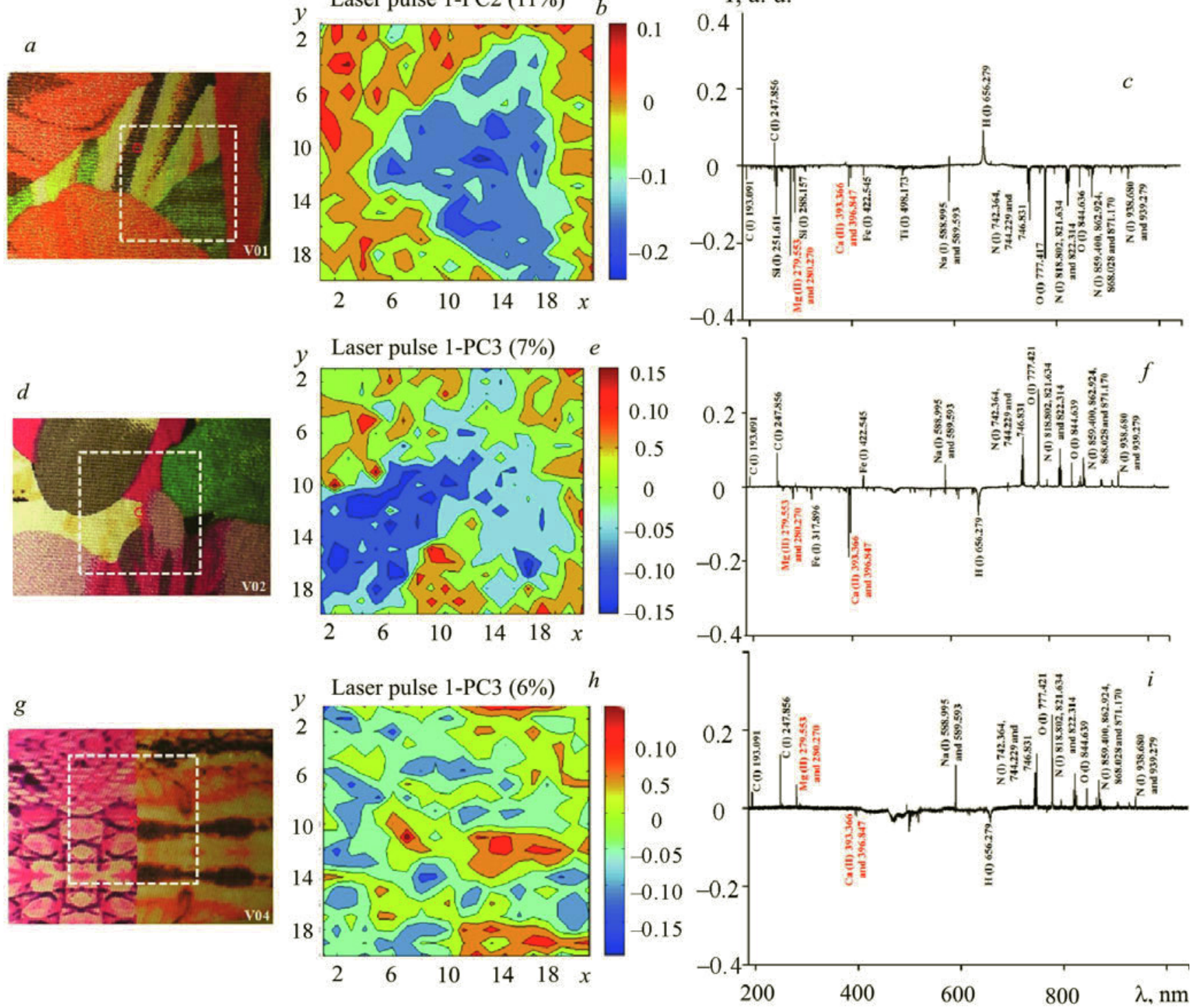

Fig. S1. Three different samples of commercial woven fabrics V01, V02, and V04 $(a, d, g)$ as well as their respective scores maps $(b, e, h)$ and loadings (c, f, i). The white dotted square in parts a, $\mathrm{d}$, and $\mathrm{g}$ represents the ablated area. 

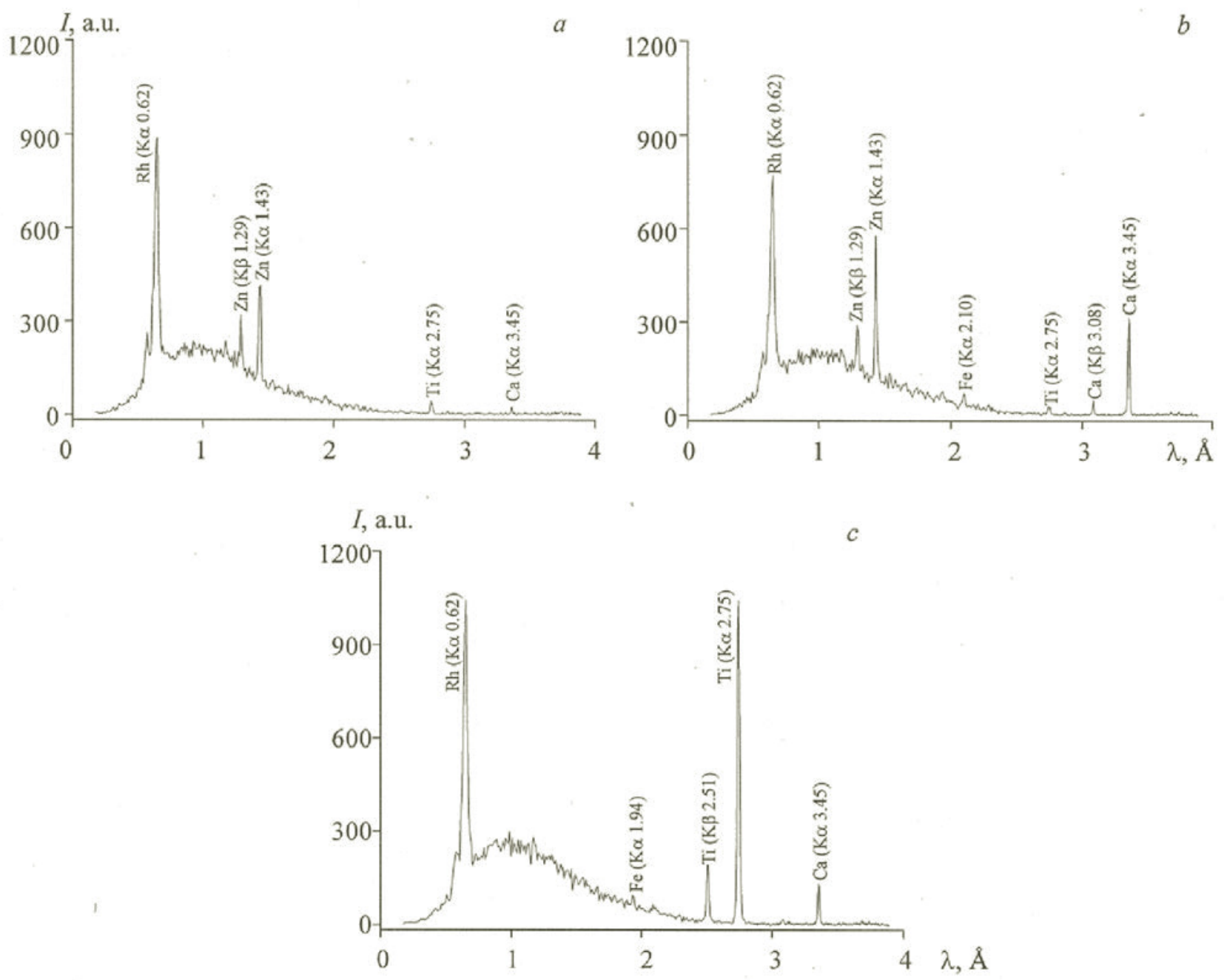

Fig. S2. WD XRF spectra acquired for commercial woven fabrics denoted as V01 (a), V02 (b), and V04 (c). 